University of South Carolina

Scholar Commons

$11-1999$

\title{
Tracking of Physical Activity, Physical Inactivity, and Health- Related Physical Fitness in Rural Youth
}

\author{
Russell R. Pate \\ University of South Carolina - Columbia, rpate@mailbox.sc.edu \\ Stewart G. Trost \\ Marsha Dowda \\ University of South Carolina - Columbia, mdowda@mailbox.sc.edu \\ Alise E. Ott \\ Dianne S. Ward
}

See next page for additional authors

Follow this and additional works at: https://scholarcommons.sc.edu/

sph_physical_activity_public_health_facpub

Part of the Public Health Commons

Publication Info

Published in Pediatric Exercise Science, Volume 11, Issue 4, 1999, pages 364-376.

Pate, R. R., Trost, S. G., Dowda, M., Ott, A. E., Ward, D. S., Saunders, R., \& Felton, G. (1999). Tracking of physical activity, physical inactivity, and health-related physical fitness in rural youth. Pediatric Exercise Science, 11(4), 364-376.

(C) Pediatric Exercise Science, 1999, Human Kinetics

This Article is brought to you by the Physical Activity and Public Health at Scholar Commons. It has been accepted for inclusion in Faculty Publications by an authorized administrator of Scholar Commons. For more information, please contact digres@mailbox.sc.edu. 


\section{Author(s)}

Russell R. Pate, Stewart G. Trost, Marsha Dowda, Alise E. Ott, Dianne S. Ward, Ruth P. Saunders, and Gwen A. Felton 


\title{
Tracking of Physical Activity, Physical Inactivity, and Health-Related Physical Fitness in Rural Youth
}

\section{Russell R. Pate, Stewart G. Trost, Marsha Dowda, Alise E. Ott, Dianne S. Ward, Ruth Saunders, and Gwen Felton}

\begin{abstract}
This study examined the tracking of selected measures of physical activity, inactivity, and fitness in a cohort of rural youth. Students $(N=181,54.7 \%$ female, $63.5 \%$ African American) completed test batteries during their fifth(age $=10.7 \pm 0.7$ years), sixth-, and seventh-grade years. The Previous Day Physical Activity Recall (PDPAR) was used to assess 30-min blocks of vigorous physical activity (VPA), moderate-to-vigorous physical activity (MVPA), TV watching and other sedentary activities, and estimated energy expenditure (EE). Fitness measures included the PWC 170 cycle ergometer test, strength tests, triceps skinfold thickness, and BMI. Intraclass correlation coefficients (ICCs) for VPA, MVPA, and after-school EE ranged from 0.63 to 0.78 . ICCs ranged from 0.49 to 0.71 for measures of inactivity and from 0.78 to 0.82 for the fitness measures. These results indicate that measures of physical activity, inactivity, and physical fitness tend to track during the transition from elementary to middle school.
\end{abstract}

The health benefits of regular physical activity and physical fitness among adults are well established $(19,30)$. Less well understood are the health benefits associated with physical activity and physical fitness among children and adolescents. While available evidence indicates that physical activity and physical fitness are inversely associated with several risk factors for cardiovascular disease $(2,22)$, the effects of childhood physical activity and fitness on long-term health outcomes remains poorly understood. One frequently cited long-term health benefit is that physically active, physically fit youth are likely to become physically active, physically fit adults. That is, like other risk factors for cardiovascular disease-serum cholesterol (12), blood pressure (8), and cigarette smoking (25)—physical activity behavior and physical fitness track over time.

To date, a relatively small number of studies have examined the tendency of physical activity behavior to track during childhood and adolescence. These studies vary considerably with respect to length of follow-up, population studied, assessment

The authors are with the Department of Exercise Science at the University of South Carolina, Columbia, SC 29208. 
of physical activity, and analytical method used to assess tracking. Yet, despite these inconsistencies, there is suggestive evidence that, over relatively short time intervals (3-5 years), physical activity behavior tracks over time $(10,18,21,23)$. Over longer periods of follow-up (6-10 years), the evidence supporting the existence of tracking is less compelling (14); however, data from several longitudinal studies indicate that youth at the extremes of the physical activity distribution (i.e., those with the highest and lowest levels of physical activity) tend to retain their relative ranking with respect to physical activity over time (20). In support of these findings, a recent longitudinal study of Finnish youth reported participation in organized sports during childhood to be a significant predictor of physical activity in young adulthood (26).

The tracking of one or more components of health-related physical fitness during childhood and adolescence has also received little research attention. Among adolescent youth, short term tracking coefficients for weight relative maximal aerobic power $\left(\mathrm{VO}_{2} \mathrm{max}\right)$ range from moderate to strong (9). However, over longer time periods ( $>5$ years), the tendency for cardiorespiratory fitness to track declines considerably $(1,11,14)$. Various indices of strength have also been examined for their tendency to track during childhood and adolescence. The results of these studies indicate a low to moderate tendency for strength to track during childhood and adolescence $(14,16)$. The tendency of body composition to track during childhood and adolescence has been studied somewhat more extensively. Results from these studies indicate that body composition measures taken during childhood and adolescence are strongly predictive of obesity status later in life $(6,32)$.

While there is some information regarding the tracking of physical activity behavior and fitness within developmental stages (e.g., early childhood, late adolescence), relatively little is known regarding the tracking of physical activity and physical fitness during the transition from elementary to middle school. This transitional period is of special interest because (a) it is a stage during which rapid physical, psychological, and social development occur (15); and (b) it is a period characterized by marked changes in physical activity and fitness (30). In addition, there is a paucity of information regarding the tracking of physical activity behavior and health-related physical fitness in rural African-American youth-a population group with a disproportionately high risk for morbidity and mortality from cardiovascular disease $(4,34)$. Therefore, the purpose of this study was to examine the tracking characteristics of physical activity and health-related physical fitness in a cohort of rural, predominantly African-American children across the fifth, sixt-, and seventh grades. Further, in order to learn more about the stability of physical inactivity within our cohort, we examined the tracking characteristics of common sedentary activities such as television watching, talking on the telephone, doing homework, and listening to music.

\section{Methods}

\section{Subjects}

All fifth-grade students from a single school district in rural South Carolina were eligible for participation in this study. Approximately $92 \%$ of the students $(N=$ 269) agreed to participate and provided baseline data during the spring of their fifth-grade year. Of this group, 181 (67.3\%) provided data during each of the fol- 
low-up assessments in sixth and seventh grades. Table 1 provides descriptive data for the baseline sample and the subgroup of students who provided physical activity and physical fitness data in the fifth, sixth, and seventh grades. The subgroup included a somewhat higher percentage of females, but both samples had similar fractions of African Americans. No differences were detected between students in the final sample and those lost to follow-up for the physical activity or fitness variables with the exception of television watching/playing video games for which the final sample reported significantly $(p=.02)$ fewer 30-min blocks than those lost to follow-up. Prior to participation in the study, written informed consent was obtained from each student and his or her guardian. The study was approved by the University of South Carolina Institutional Review Board.

\section{Measurement of Physical Activity}

Physical activity during the after-school hours was assessed using the Previous Day Physical Activity Recall (PDPAR). This self-report instrument made use of a standardized form organized into seventeen 30-min blocks beginning at 3:00 P.M. and continuing through 11:30 P.M. Thirty-five common activities, including sedentary activities such as television watching, were listed on the form, and each student entered the main activity in which he or she participated during each of the 30-min time periods on the previous day. A detailed description of the PDPAR can be found elsewhere (33). The PDPAR has established validity based on concurrent observation with both motion sensors $(r=0.77)$ and heart rate monitors $(r=0.63)$, and established test-retest reliability $(r=.98)(33)$.

Students completed the PDPAR instrument on 3 consecutive days in the classroom under the supervision of two trained staff members. Data from each day were reduced to the average number of 30-min blocks in which the main activity was rated $\geq 6 \mathrm{METs}$, vigorous physical activity (VPA) — and $\geq 3 \mathrm{METs}$, moderate-to-vigorous physical activity (MVPA). In addition, MET values ( $\mathrm{kcal} / \mathrm{kg} / \mathrm{hr}$ ) for each 30 -min block were used to estimate energy expenditure during the after-school period. The PDPAR was also used to estimate the average number of 30-min blocks in which the main

Table 1 Demographic Characteristics of Baseline Samples and the Subgroup of Students Who Completed Assessments in Grades 5, 6, and 7

\begin{tabular}{|c|c|c|c|c|}
\hline \multirow[b]{2}{*}{ Variable } & \multicolumn{2}{|c|}{$\begin{array}{l}\text { Baseline sample } \\
\qquad(N=269)\end{array}$} & \multicolumn{2}{|c|}{$\begin{array}{l}\text { Subgroup } \\
(N=181)\end{array}$} \\
\hline & $N$ & $\%$ & $N$ & $\%$ \\
\hline \multicolumn{5}{|l|}{ Gender } \\
\hline Male & 140 & 52.0 & 82 & 45.3 \\
\hline Female & 129 & 48.0 & 99 & 54.7 \\
\hline \multicolumn{5}{|l|}{ Race } \\
\hline White & 90 & 33.5 & 66 & 36.5 \\
\hline Black & 179 & 66.5 & 115 & 63.5 \\
\hline Age $(M \pm S D)$ & \multicolumn{2}{|c|}{$10.7 \pm 0.7$} & \multicolumn{2}{|c|}{$10.7 \pm 0.7$} \\
\hline
\end{tabular}


activity was television watching or playing video games and "other sedentary behaviors," which included talking on the telephone, doing homework, and listening to music.

\section{Health Related Fitness Measures}

Cardiorespiratory Fitness. Cardiorespiratory fitness was assessed via the Physical Work Capacity 170 test (PWC 170) using a Monark cycle ergometer (24). Students performed three 3-min stages at a cadence of $60 \mathrm{rpm}$. Power outputs for each stage were selected to elicit heart rates of approximately 120,150, and 180 beats per minute. Heart rate during the last minute of each exercise stage was recorded via a Polar Vantage XL heart rate monitor. Individual simple linear regression analyses were then used to predict the power output required to elicit a heart rate of 170 beats $\cdot \mathrm{min}^{-1}$. To control for differences in body size, power outputs were expressed relative to body weight.

Upper Body Strength. Maximal shoulder extension and elbow flexion were measured via isometric cable tensiometer strength tests as described by Clarke et al. (7). For each measure, three trials were performed with the highest score taken as the actual measure. To control for differences in body size, both measures were expressed relative to body weight.

Body Composition. Anthropometric measurements included height, body weight, and triceps skinfold measurements. Height was measured to the nearest $1.0 \mathrm{~cm}$ with a portable stadiometer. Body weight was measured to the nearest 0.2 $\mathrm{kg}$ with a standard beam scale. For the triceps skinfold measurements, the right mid-upper arm was measured and marked, and three separate measures were obtained using calibrated Lange skinfold calipers. The average of the three measurements were used in the analysis. Body Mass Index (BMI) was calculated as body weight in kilograms divided by height in meters squared $\left(\mathrm{kg} \cdot \mathrm{m}^{2}\right)$.

\section{"At-Risk" Status}

To determine if fifth-grade students "at risk" for low levels of physical activity and health related physical fitness remained at risk some 2 years later in the seventh grade, students were grouped into risk categories in Years 1 and 3 of the study. For physical activity behavior, students were classified as at-risk according to a vigorous activity criterion and a moderate activity criterion. The moderate activity criterion classified students as "at risk" if they reported less than two 30-min time blocks with physical activity at an intensity $\geq 3$ METs. This addresses the recommendation by the Health Education Authority (3) that all young people should participate in physical activity of at least moderate intensity for 1 hour per day. The vigorous activity criterion classified students as at risk if they averaged less than one 30-min block of vigorous activity ( $\geq 6$ METs) on a daily basis, which addresses the Healthy People 2000 goal 1.4 , of vigorous physical activity on 3 or more days that lasts 20 min or longer (30). For estimated after-school energy expenditure, cardiorespiratory fitness, shoulder flexion, and elbow flexion, at-risk status was defined as ranking in the lowest genderspecific quartile. For the measures of body composition, students were classified as overweight and hence at risk if their BMI or triceps skinfold thickness was equal to or greater than the sex-, race-, and age-specific 85th percentile of the first National Health and Nutrition Survey (NHANES I) (17, 27). For television watching, subjects were classified as "at risk" if they reported three or more 30-min blocks in which the main 
activity was television watching or playing video games. Similarly, with respect to the outcome variable "other sedentary behaviors," students were classified as "at risk" if they reported three or more 30-min blocks in which the main activity was either talking on the phone, doing homework, or listening to music.

\section{Statistical Analysis}

Four statistical procedures were used to determine the magnitude of tracking. Pearson correlation coefficients were calculated between Years 1 and 3. Additionally, repeated measures ANOVA was used to calculate the intraclass correlation coefficient (ICC), which was a summary value for observations from 3 years for each dependent variable. Percent agreement and the modified Kappa statistics (13) between Years 1 and 3 were also calculated to determine the extent to which individuals remained in their respective risk categories over time. Analyses were performed on the entire sample as well as on a gender-specific basis. Significance was set at an alpha level of 0.05 .

\section{Results}

\section{Physical Activity}

Means and standard deviations, correlation coefficients, and measures of agreement (percent agreement and modified Kappa statistics) for the physical activity measures are presented in Table 2. Within the entire sample, tracking coefficients for VPA, MVPA, and after-school energy expenditure were statistically significant $(p<.01)$ and ranged from 0.24 to 0.41 . ICCs for mean VPA, MVPA, and afterschool energy expenditure over the three observations were $0.68,0.63$, and 0.78 , respectively. Percent agreement statistics for physical activity status in Years 1 and 3 of the study ranged from 66 to $70 \%$, while Kappa for the corresponding time period ranged from 0.32 to 0.40 . Tracking coefficients and measures of agreement were generally stronger in males than females.

\section{Sedentary Behavior}

Means and standard deviations, correlation coefficients, and measures of agreement for the sedentary activities are presented in Table 3 . Within the entire sample, correlation coefficients were statistically significant $(p<.001)$ and ranged from 0.25 to 0.41 . The ICCs for television watching/playing video games and the other sedentary behaviors (time spent talking on the telephone, doing homework, and/or listening to music) were 0.71 and 0.49 , respectively. Percent agreement statistics for television watching/playing video games and the other sedentary behaviors in Years 1 and 3 of the study were $65 \%$ and 57\%, respectively, while Kappas for corresponding time period were 0.30 and 0.14 , respectively. Tracking coefficients and measures of agreement for the sedentary behaviors were generally stronger in males than females.

\section{Measures of Health-Related Physical Fitness}

Means and standard deviations, correlation coefficients, and measures of agreement for cardiorespiratory fitness and upper body strength are presented in Table 4. Within 
Table 2 Means and Standard Deviations, Correlation Coefficients, Percent Agreement, and Modified Kappa Statistics for the Physical Activity Measures

\begin{tabular}{|c|c|c|c|c|c|c|c|}
\hline $\begin{array}{l}\text { Phyical } \\
\text { activity } \\
\text { measure }\end{array}$ & Year & $N$ & $M \pm S D$ & $\begin{array}{l}\text { Pearson } \\
\text { correlation } \\
1 \text { and } 3\end{array}$ & $\begin{array}{l}\text { Intraclass } \\
\text { correlation } \\
\text { (ICC) }\end{array}$ & $\begin{array}{c}\text { Percent } \\
\text { agreement } \\
1 \text { and } 3\end{array}$ & $\begin{array}{l}\text { Kappa } \\
1 \text { and } 3\end{array}$ \\
\hline \multicolumn{8}{|l|}{ Total } \\
\hline \multirow[t]{3}{*}{ VPA } & 1 & 181 & $1.9 \pm 1.6$ & $0.36 * * *$ & 0.68 & 66 & 0.32 \\
\hline & 2 & & $2.1 \pm 1.7$ & & & & \\
\hline & 3 & & $1.7 \pm 1.7$ & & & & \\
\hline \multirow[t]{3}{*}{ MVPA } & 1 & 181 & $2.9 \pm 1.8$ & $0.24 * *$ & 0.63 & 66 & 0.32 \\
\hline & 2 & & $3.0 \pm 1.8$ & & & & \\
\hline & 3 & & $2.6 \pm 2.0$ & & & & \\
\hline \multirow[t]{3}{*}{ Kcals } & 1 & 181 & $856 \pm 362$ & $0.41 * * *$ & 0.78 & 70 & 0.40 \\
\hline & 2 & & $979 \pm 375$ & & & & \\
\hline & 3 & & $1026 \pm 407$ & & & & \\
\hline \multicolumn{8}{|l|}{ Males } \\
\hline \multirow[t]{3}{*}{ VPA } & 1 & 82 & $2.7 \pm 1.7$ & $0.23^{*}$ & 0.61 & 73 & 0.46 \\
\hline & 2 & & $2.8 \pm 1.8$ & & & & \\
\hline & 3 & & $2.5 \pm 1.9$ & & & & \\
\hline \multirow[t]{3}{*}{ MVPA } & 1 & 82 & $3.6 \pm 1.8$ & 0.08 & 0.61 & 68 & 0.36 \\
\hline & 2 & & $3.7 \pm 1.8$ & & & & \\
\hline & 3 & & $3.3 \pm 2.0$ & & & & \\
\hline \multirow[t]{3}{*}{ Kcals } & 1 & 82 & $979 \pm 397$ & $0.38 * *$ & 0.81 & 78 & 0.56 \\
\hline & 2 & & $1098 \pm 396$ & & & & \\
\hline & 3 & & $1191 \pm 448$ & & & & \\
\hline \multicolumn{8}{|l|}{ Females } \\
\hline \multirow[t]{3}{*}{ VPA } & 1 & 99 & $1.3 \pm 1.3$ & $0.23^{*}$ & 0.50 & 61 & 0.21 \\
\hline & 2 & & $1.5 \pm 1.3$ & & & & \\
\hline & 3 & & $1.1 \pm 1.3$ & & & & \\
\hline \multirow[t]{3}{*}{ MVPA } & 1 & 99 & $2.3 \pm 1.6$ & 0.20 & 0.55 & 65 & 0.29 \\
\hline & 2 & & $2.4 \pm 1.6$ & & & & \\
\hline & 3 & & $2.0 \pm 1.7$ & & & & \\
\hline \multirow[t]{3}{*}{ Kcals } & 1 & 99 & $756 \pm 298$ & $0.25^{*}$ & 0.63 & 70 & 0.40 \\
\hline & 2 & & $882 \pm 329$ & & & & \\
\hline & 3 & & $891 \pm 315$ & & & & \\
\hline
\end{tabular}

Note. VPA $=$ Number of 30-min blocks with activity rated $\geq 6$ METs. MVPA $=$ Number of 30 -min blocks with activity rated $\geq 3$ METs. Kcals = Estimated energy expenditure for the after school period (3:00-11:30 p.m.).

${ }^{*} p<.05 ;{ }^{* *} p<.01 ; * * * p<.001$.

the entire sample, the tracking coefficient for PWC 170 scores was 0.65 and was statistically significant at $p<.001$. The ICC for the PWC 170 test was 0.82 . Percent agreement statistics for the PWC 170 quartiles in Years 1 and 3 of the study was $82 \%$, while Kappa was 0.64 . Within gender groups, PWC 170 scores exhibited similar trends, with the tracking coefficients being somewhat stronger in males 
Table 3 Means and Standard Deviations, Correlation Coefficients, Percent Agreement, and Modified Kappa Statistics for Selected Sedentary Activities

\begin{tabular}{|c|c|c|c|c|c|c|c|}
\hline $\begin{array}{l}\text { Physical } \\
\text { activity }\end{array}$ & Year & $N$ & $M \pm S D$ & $\begin{array}{c}\text { Pearson } \\
\text { correlation } \\
1 \text { and } 3\end{array}$ & $\begin{array}{l}\text { Intraclass } \\
\text { correlation } \\
\text { (ICC) }\end{array}$ & $\begin{array}{c}\text { Percent } \\
\text { agreement } \\
1 \text { and } 3\end{array}$ & $\begin{array}{l}\text { Kappa } \\
1 \text { and } 3\end{array}$ \\
\hline
\end{tabular}

Total

TV/games ${ }^{1}$

$\begin{array}{lllllll}1 & 181 & 3.2 \pm 1.9 & 0.41^{* *} & 0.71 & 65 & 0.30 \\ 2 & & 3.1 \pm 2.0 & & & & \\ 3 & & 3.1 \pm 2.0 & & & & \end{array}$

Phone/homework/music ${ }^{2}$

$\begin{array}{lllllll}1 & 181 & 1.9 \pm 1.3 & 0.25 * * & 0.49 & 57 & 0.14 \\ 2 & & 1.5 \pm 1.1 & & & & \\ 3 & & 2.3 \pm 1.7 & & & & \end{array}$

Males

TV/games ${ }^{1}$

$\begin{array}{lll}1 & 82 & 3.6 \pm 2.0 \\ 2 & & 3.3 \pm 2.1 \\ 3 & & 3.4 \pm 2.0\end{array}$

$$
0.42 * *
$$

72

0.44

Phone/homework/music ${ }^{2}$

Females

$\begin{array}{lllllll}1 & 82 & 1.7 \pm 1.2 & 0.27 * & 0.54 & 57 & 0.14 \\ 2 & & 1.4 \pm 1.2 & & & & \\ 3 & & 1.8 \pm 1.7 & & & & \end{array}$

TV/games ${ }^{1}$

$\begin{array}{ccrrrrr}\text { Phone/homework/music } & & & & & \\ 1 & 99 & 2.1 \pm 1.3 & 0.17 & 0.39 & 58 & 0.16 \\ 2 & & 1.5 \pm 1.0 & & & & \\ 3 & & 2.7 \pm 1.6 & & & & \end{array}$

\footnotetext{
${ }^{1}$ Number of 30-min blocks in which the main activity was TV watching or playing video games.

${ }^{2}$ Number of 30 -min blocks in which the main activity was talking on phone, doing homework, or listening to music.

$* p<.05 ; * * p<.001$.
}

(0.53) than females $(0.68)(p<.001)$. The measures of upper body strength demonstrated similar tracking tendencies. The correlation coefficients for elbow and shoulder flexion were 0.53 and $0.64(p<.001)$, and the ICCs were 0.79 and 0.78 , respectively. Percent agreement statistics for the elbow and shoulder flexion quartiles were $77 \%$ and $79 \%$, while Kappa was 0.54 and 0.58 . Within gender groups, the strength measures exhibited similar tracking tendencies, with ICCs being somewhat stronger in males ( 0.81 and 0.82$)$ than females. 
Table 4 Means and Standard Deviations, Correlation Coefficients, Percent Agreement, and Modified Kappa Statistics for Selected Measures of Health Related Physical Fitness

\begin{tabular}{|c|c|c|c|c|c|c|c|}
\hline Measure & Year & $N$ & $M \pm S D$ & $\begin{array}{c}\text { Pearson } \\
\text { correlation } \\
1 \text { and } 3\end{array}$ & $\begin{array}{l}\text { Intraclass } \\
\text { correlation } \\
\text { (ICC) }\end{array}$ & $\begin{array}{c}\text { Percent } \\
\text { agreement } \\
1 \text { and } 3\end{array}$ & $\begin{array}{l}\text { Kappa } \\
1 \text { and } 3\end{array}$ \\
\hline
\end{tabular}

Total

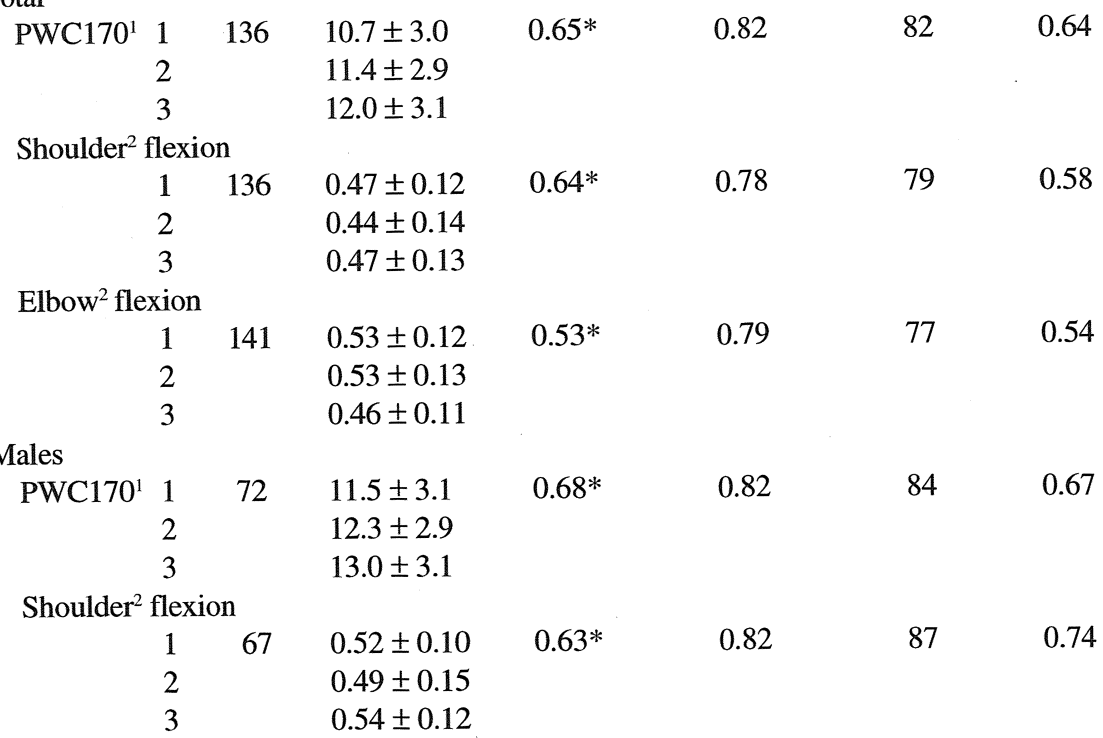

Elbow ${ }^{2}$ flexion

$\begin{array}{lllllll}1 & 72 & 0.56 \pm 0.11 & 0.52^{*} & 0.81 & 81 & 0.62 \\ 2 & & 0.56 \pm 0.14 & & & & \\ 3 & & 0.50 \pm 0.13 & & & & \end{array}$

Females

\begin{tabular}{|c|c|c|c|c|c|c|c|}
\hline \multirow[t]{3}{*}{$\mathrm{PWC} 170^{1}$} & 1 & 64 & $9.8 \pm 2.7$ & $0.53 *$ & 0.76 & 88 & 0.75 \\
\hline & 2 & & $10.3 \pm 2.5$ & & & & \\
\hline & 3 & & $11.0 \pm 2.7$ & & & & \\
\hline \multicolumn{8}{|c|}{ Shoulder ${ }^{2}$ flexion } \\
\hline & 1 & 69 & $0.43 \pm 0.11$ & $0.50 *$ & 0.75 & 75 & 0.50 \\
\hline & 2 & & $0.40 \pm 0.11$ & & & & \\
\hline & 3 & & $0.41 \pm 0.11$ & & & & \\
\hline
\end{tabular}

Elbow ${ }^{2}$ flexion

$\begin{array}{llllll}69 & 0.51 \pm 0.12 & 0.52 * & 0.71 & 75 & 0.50 \\ 0.51 \pm 0.11 & & & & \\ 0.43 \pm 0.08 & & & & \end{array}$

${ }^{1} \mathrm{Kg} \cdot \mathrm{m} \cdot \mathrm{Kg}$ bwt $^{-1}$

${ }^{2} \mathrm{Kg} \cdot \mathrm{Kg} \mathrm{bwt}^{-1}$

$* p<.001$. 
Table 5 Means and Standard Deviations, Correlation Coefficients, Percent Agreement, and Modified Kappa Statistic for the Body Composition Measures

\begin{tabular}{|c|c|c|c|c|c|c|c|}
\hline Measure & Year & $N$ & $M \pm S D$ & $\begin{array}{c}\text { Pearson } \\
\text { correlation } \\
1 \text { and } 3\end{array}$ & $\begin{array}{l}\text { Intraclass } \\
\text { correlation } \\
\text { (ICC) }\end{array}$ & $\begin{array}{c}\text { Percent } \\
\text { agreement } \\
1 \text { and } 3\end{array}$ & $\begin{array}{l}\text { Kappa } \\
1 \text { and } 3\end{array}$ \\
\hline \multicolumn{8}{|l|}{ Total } \\
\hline \multirow[t]{3}{*}{$\mathrm{BMI}^{1}$} & 1 & 145 & $19.6 \pm 3.8$ & $0.86^{*}$ & 0.97 & 84 & 0.68 \\
\hline & 2 & & $21.7 \pm 3.7$ & & & & \\
\hline & 3 & & $21.6 \pm 3.9$ & & & & \\
\hline \multicolumn{8}{|c|}{ Tricep skinfold (mm) } \\
\hline & 1 & 142 & $12.3 \pm 5.9$ & $0.85^{*}$ & 0.87 & 82 & 0.64 \\
\hline & 2 & & $16.1 \pm 8.1$ & & & & \\
\hline & 3 & & $17.1 \pm 8.4$ & & & & \\
\hline \multicolumn{8}{|l|}{ Males } \\
\hline \multicolumn{8}{|l|}{$\mathrm{BMII}^{1}$} \\
\hline & 1 & 75 & $19.8 \pm 3.9$ & $0.90 *$ & 0.98 & 84 & 0.68 \\
\hline & 2 & & $21.0 \pm 3.9$ & & & & \\
\hline & 3 & & $21.8 \pm 4.0$ & & & & \\
\hline \multicolumn{8}{|c|}{ Tricep skinfold (mm) } \\
\hline & 1 & 73 & $12.1 \pm 6.3$ & $0.87 *$ & 0.86 & 79 & 0.58 \\
\hline & 2 & & $15.6 \pm 8.2$ & & & & \\
\hline & 3 & & $15.6 \pm 8.0$ & & & & \\
\hline \multicolumn{8}{|l|}{ Females } \\
\hline \multicolumn{8}{|l|}{$\mathrm{BMII}^{1}$} \\
\hline & 1 & 70 & $19.5 \pm 3.7$ & $0.81^{*}$ & 0.95 & 84 & 0.68 \\
\hline & 2 & & $20.4 \pm 3.5$ & & & & \\
\hline & 3 & & $21.3 \pm 3.9$ & & & & \\
\hline \multicolumn{8}{|c|}{ Tricep skinfold (mm) } \\
\hline & 1 & 69 & $12.6 \pm 5.5$ & $0.86^{*}$ & 0.85 & 85 & 0.70 \\
\hline & 2 & & $16.5 \pm 7.9$ & & & & \\
\hline & 3 & & $18.6 \pm 7.9$ & & & & \\
\hline
\end{tabular}

${ }^{1}$ Body Mass Idex $\left(\mathrm{Kg} / \mathrm{m}^{2}\right)$.

$* p<.001$.

Means and standard deviations, correlation coefficients, and measures of agreement for the body composition measures are presented in Table 5. Both BMI and triceps skinfold measures demonstrated strong tracking tendencies. Within the entire sample, the correlation coefficients were 0.86 and 0.85 , while the ICCs for mean BMI and triceps skinfold thickness were 0.97 and 0.87 , respectively. Similar tracking coefficients were observed among the males and females. The percentage of students classified as overweight, using the 85th percentile of BMI, in Years 1, 2, and 3 was $35.2 \%, 35.9 \%$, and $38.6 \%$. Percent agreement statistics for BMI and triceps skinfold thickness measured in Years 1 and 3 of the study were $84 \%$ and $82 \%$, respectively, while Kappas over the corresponding time period were 0.68 and 0.64 , respectively. Measures of agreement did not differ markedly between males and females. 


\section{Discussion}

No previous study has simultaneously examined the tracking characteristics of physical activity, sedentary behaviors such as television watching, and selected measures of health-related physical fitness. Furthermore, this study was unique in that the observations were made in a cohort of rural, predominantly African-American youth. Our key overall finding was that fifth-grade students classified as at risk for low levels of physical activity and healthrelated physical fitness tended to remain at risk 2 years later in the seventh grade. This finding is consistent with the view that public health initiatives to promote lifelong physical activity should begin early in life before behavioral patterns are fully established $(2,5)$.

Previous studies of children and adolescents have reported low to moderate tracking coefficients for physical activity behavior $(1,18,23)$. Within our cohort of rural, predominantly African-American children, the correlation between the physical activity measures taken in the fifth and seventh grades ranged from 0.24 to 0.41 , indicating a relatively low level of tracking. However, when participants were grouped into risk categories for low physical activity, there was a stronger tendency for individuals to remain in the same risk category from year to year. Percent agreement statistics for the physical activity classifications in Year 1 (fifth grade) and Year 3 (seventh grade) ranged from 66 to 77\%, while Kappa for the same years ranged from 0.32 to 0.40 . Therefore, in agreement with the results of some previous longitudinal studies $(10,20)$, there was a tendency for individuals at the extremes of the physical activity distribution (highest and lowest) to maintain their physical activity status during the transition from the fifth to the seventh grade. This suggests that intervention programs to increase physical activity in elementary students are warranted.

Previous longitudinal studies have examined the tracking of physical inactivity by assessing the maintenance of low activity status over time. In the Young Finns Study (20), 57\% of the children initially classified as sedentary at baseline were sedentary in a 6-year follow-up. Similarly, in the Amsterdam Growth Study (29), $57.1 \%$ of the boys and $29.2 \%$ of the girls in the lowest quintile for energy expenditure at age 13 remained in the lowest quintile 4 years later at age 16 .

In the present study, we adopted a unique approach to examining the tracking of physical inactivity. Specific sedentary behaviors such as television watching, playing video games, and talking on the phone were examined for their tendency to track over the 2-year study period. Our results indicated that time spent watching television or playing video games tracks moderately well from the fifth to the seventh grade, while the combination of sedentary activities consisting of talking on the phone, doing homework, and listening to music tracks somewhat poorly over time. Thus, within our cohort, there appears to be a somewhat stable group of youngsters who spend considerable time engaged primarily in sedentary pursuits such as television watching and playing video games. This observation supports and extends the findings of previous longitudinal studies and suggests that certain sedentary activities track over time. The tracking of specific sedentary behaviors deserves further research attention.

Consistent with the results of previous investigations involving other populations of youth $(9,14,16)$, the measures of health-related physical fitnesscardiorespiratory endurance, upper body strength, and body composition- 
exhibited a moderate to strong tendency to track from the fifth to the seventh grade. Within the entire cohort, tracking coefficients for cardiorespiratory fitness, upper body strength, and body composition measures ranged from 0.53 to 0.94 . In agreement with these observations, there was strong evidence that individuals tended to remain in their respective risk category from year to year. Percent agreement statistics for the health-related fitness classifications in Year 1 and 3 of the study ranged from 77 to $84 \%$, while Kappa statistics for the same period exceeded 0.50 . The moderate to strong tracking characteristics of selected measures of health-related physical fitness were not unexpected. Fitness parameters such as cardiorespiratory endurance, upper body strength, and body composition are influenced by genetic factors (15) and are dependent on biological growth and development, which have been shown to have their own tracking properties (14). Furthermore, in contrast to physical activity, which is a complex behavior not easily measured in young children (2), cardiorespiratory fitness, upper body strength, and body composition can be very reliably measured via objective measurement protocols. Hence, the higher tracking coefficients observed for the fitness variables relative to physical activity may also be a reflection of the smaller amount of random measurement error in the fitness measures.

This study had several limitations that warrant consideration. First, compared to some previous tracking studies, our follow-up period of 2 years was relatively short. Therefore, our conclusions regarding the tracking of physical activity and fitness should be interpreted with some degree of caution. Second, our conclusions regarding the tracking of physical activity and specific sedentary behaviors were based on 3 days of self-reported data and therefore may not be representative of each subject's usual activity behavior. A strength of this study was our use of multiple indices of tracking (28). In addition to the conventional interperiod correlation coefficient, we calculated the 3-year intraclass correlation coefficient for each of the physical activity and health-related fitness measures. We also examined the extent to which youngsters remained in their respective risk categories from year to year by calculating percent agreement and modified Kappa statistics. Consequently, our conclusions regarding the tendency of physical activity behavior and physical fitness to track from the fifth to the seventh grades were based on several sources of complementary information.

The findings of the present study carry important implications for policy and practice in the fields of public health, medicine, education, and community recreation. Health authorities generally agree that primary prevention of chronic disease should be a major thrust of societal efforts to promote health in the 21 st century. Such efforts will be most efficient and effective if they are focused on those segments of the population that are at greatest risk of developing chronic diseases. The results of this study suggest that there is a relatively stable sub-group of young persons who manifest low levels of physical activity. Targeting this group with interventions to promote increased physical activity would exemplify, we believe, the primary prevention strategy that we hope will characterize future efforts to reduce chronic disease risk in the population.

In summary, a substantial percentage of fifth-grade students classified as at risk for low levels of physical activity and health-related physical fitness remained at risk 2 years later in the seventh grade. Additional studies, with longer follow-up periods and more sophisticated measures of physical activity and physical inactivity should be performed to confirm these findings. 


\section{References}

1. Anderson, L.B., and J. Haraldsdóttir. Tracking of cardiovascular disease risk factors including maximal oxygen uptake and physical activity from late teenage to adulthood an 8year follow-up study. J. Intern. Med. 234:309-315, 1993.

2. Baranowski, T., C. Bouchard, O. Bar-Or, et al. Assessment, prevalence, and cardiovascular benefits of physical activity and fitness in youth. Med. Sci. Sports Exerc. 24(Suppl.):S237-S247, 1992.

3. Biddle, S., J.F. Sallis, and N.A. Cavill. (Eds.). Young and active? Young people and health enhancing physical activity: Evidence and implications. London: Health Education Authority, 1998.

4. Centers for Disease Control and Prevention. Chronic Disease in Minority Populations. Atlanta, GA: Author, 1992.

5. Centers for Disease Control and Prevention. Guidelines for school and community programs to promote lifelong physical activity among young people. MMWR. 46(No. RR6):1-36, 1997.

6. Clarke W.R., and R.M. Lauer. Does childhood obesity track into adulthood. Crit. Rev. Food Sci. Nutr. 33:423-430, 1993.

7. Clarke, H.H., T.L. Bailey, and C.T. Shay. New objective strength tests of muscle groups by cable tension methods. Res. Q. 23:136-148, 1952.

8. Clarke, W.R., H.G. Schrott, P.E. Leaverton, W.E. Connor, and R.M. Lauer. Tracking of blood lipids and blood pressure in children: The Muscatine study. Circulation. 58:626634, 1978.

9. Janz, K.F., and L.T. Mahoney. Three-year follow-up of changes in aerobic fitness during puberty: The Muscatine study. Res. Q. Exerc. Sport. 68:1-9, 1997.

10. Kelder, S.H., C.L. Perry, K.I. Klepp, and L.L. Lytle. Longitudinal tracking of adolescent smoking, physical activity, and food choice behaviors. Am. J. Public Health. 84:11211126, 1994.

11. Kemper, H.C.G., J. Nels, and S.E.L. Verschuur. Tracking of health and risk indicators of cardiovascular diseases from teenager to adult: Amsterdam Growth and Health Study. Prev. Med. 19:642-655, 1990.

12. Laskarzewski, P., J.A. Morrison, I. deGroot, K.A. Kelly, M.J. Mellies, P. Khoury, and C.J. Glueck. Lipid and lipoprotein tracking in 108 children over a four-year period. Pediatr. 64:585-591, 1979.

13. Looney, M.A. Criterion-references measurement: Reliability. In: Measurement Concepts in Physical Education and Exercise Science, M.J. Safrit and T.M. Wood (Eds.). Champaign, IL: Human Kinetics, 1989, pp. 137-152.

14. Malina, R.M. Tracking of physical activity and physical fitness across the lifespan. Res. Q. Exerc. Sport. 67(Suppl.): S48-S57, 1996.

15. Malina, R.M., and C. Bouchard. Growth, Maturation, and Physical Activity. Champaign, IL: Human Kinetics, 1991.

16. Marshall, G.J., J.A. Sarkin, J.F. Sallis, and T.L. McKenzie. Tracking of health-related fitness components in youth ages 9 to 12. Med. Sci. Sports Exerc. 30:910-916, 1998.

17. Must, A., G.E. Dallal, and W.H. Dietz. Reference data for obesity: 85th and 95th percentiles of body mass index $\left(\mathrm{wt} / \mathrm{ht}^{2}\right)$ and triceps skinfold thickness. Am. J. Clin. Nutr. 53:839846, 1991.

18. Pate, R.R., T. Baranowski, M. Dowda, and S.G. Trost. Tracking of physical activity in young children. Med. Sci. Sports Exerc. 28:92-96, 1996.

19. Pate, R.R., M. Pratt, S.N. Blair, W.L. Haskell, C.A. Macera, C. Bouchard, D. Buchner, W. Ettinger, G.W. Heath, A.C.King, A. Kriska, A.S. Leon, B.H. Marcus, J. Morris, R.S. Paffenbarger, K. Patrick, M.L. Pollock, J.M. Rippe, J.F. Sallis, and J.H. Wilmore. Physical activity and public health: A recommendation from the Centers for Disease Control 
and Prevention and the American College of Sports Medicine. JAMA. 273:402-407, 1995.

20. Raitakari, O.T., K.V.K. Porkka, S. Taimela, R. Telama, L. Räsänen, and J.S.A. Viikari. Effects of persistent physical activity and inactivity on coronary risk factors in children and young adults the cardiovascular risk in Young Finns. Am. J. Epidemiol. 140:195-205, 1994.

21. Sallis, J.F., C.C. Berry, S.L. Broyles, T.L. McKenzie, and P.R. Nader. Variability and tracking of physical activity over 2 yr in young children. Med. Sci. Sports Exerc. 27:1042-1049, 1995.

22. Sallis, J.F., and K. Patrick. Physical activity guidelines for adolescents: Consensus statement. Ped. Exerc. Sci. 6:302-314, 1994.

23. Saris, W.H.M., J.W.H. Elvers, M.A. Van't Hof, and R.A. Binkhorst. Changes in physical activity of children aged 6 to 12 years. In: Children and Exercise XII, J. Rutenfranz and R. Mocellin (Eds.). Champaign, IL: Human Kinetics, 1989, pp. 121-130.

24. Strong, W.B., D. Spencer, M.D. Miller, and M. Salehbhai. The physical work capacity of black children. AJDC. 132:244-248, 1978.

25. Taoli, E., and E.L. Wynder. Effect of age at which smoking begins on frequency of smoking in adulthood. N. Engl. J. Med. 325:968-969, 1991.

26. Telama, R., X. Yang, L. Laakso, and J. Viikari. Physical activity in childhood and adolescence as predictor of physical activity in young adulthood. Am. J. Prev. Med. 13:317-323, 1997.

27. Troiano, R.P., and K.M. Flegal. Overweight children and adolescents: Description, epidemiology, and demographics. Pediatrics. 101:497-504, 1998.

28. Twisk, J.W.R., H.C.G. Kemper, and G.J. Mellenbergh. Mathematical and analytical aspects of tracking. Epidemiol. Rev. 16:165-183, 1994.

29. Twisk, J.W.R., H.C.G. Kemper, and J. Snel. Tracking of cardiovascular risk factors in relation to lifestyle. In: The Amsterdam Growth Study: A Longitudinal Analysis of Health Fitness and Lifestyle, H.C.G. Kemper (Ed.). Champaign, IL: Human Kinetics, 1995, pp. 203-204.

30. U.S. Department of Health and Human Services. Healthy People 2000: National Health Promotion and Disease Prevention Objectives (DHHS Publicaiton No. PHS 91-50212). Washington, DC: Government Printing Office, 1991.

31. U.S. Department of Health and Human Services. Physical Activity and Health: A Report of the Surgeon General. Atlanta, GA: U.S. Department of Health and Human Services, Centers for Disease Control and Prevention, National Center for Chronic disease Prevention and Health Promotion, 1996.

32. Van Lenthe, F.J., H.C.G. Kemper, W. Van Mechelen, and J.W.R. Twisk. Development and tracking of central patterns of subcutaneous fat in adolescence and adulthood: The Amsterdam Growth and Health Study. Int. J. Epidemiol. 25:1162-1171, 1996.

33. Weston, A.T., R. Petosa, and R.R. Pate. Validation of an instrument for measurement of physical activity in youth. Med. Sci. Sports Exerc. 29:138-143, 1997.

34. Winkleby, M.A., T.N. Robinson, J. Sundquist, and H.C. Kraemer. Ethnic variation in cardiovascular disease risk factors among children and young adults. Findings from the Third National Health and Nutrition Examination Survey, 1988-1994. JAMA. 281:1006-1013, 1999.

\section{Acknowledgment}

This study was supported by NIH grant RO1 NR03634. 